\title{
ATTITUDE OF WOMEN AND THEIR HUSBANDS REGARDING PRENATAL INVASIVE TESTING ATTENDING GENETIC CLINIC AT A TERTIARY REFERRAL CENTER, INDIA
}

\author{
Koirala $N^{1^{*}}$, Kafle $S P^{2}$
}

\begin{abstract}
Affiliation
1. Assistant Professor, Purbanchal University College of Medical and Allied Sciences, Gothgaon, Morang

2. Assistant Professor, B.P. Koirala Institute of Health Sciences, Dharan, Nepal.
\end{abstract}

\section{ARTICLE INFO}

Received : 10 May, 2020
Accepted : 22 November, 2020
Published : 22 December, 2020

(C) Authors retain copyright and grant the journal right of first publication with the work simultaneously licensed under Creative Commons Attribution License CC - BY 4.0 that allows others to share the work with an acknowledgment of the work's authorship and initial publication in this journal.

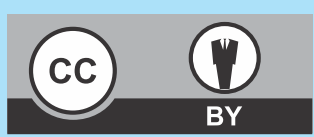

ORA 202

DOI: https://doi.org/10.3126/bjhs.v5i3.33690

\author{
* Corresponding Author \\ Dr. Namu Koirala \\ Assistant Professor \\ Purbanchal University College of Medical Sciences \\ Gothgaon, Morang \\ Email ID: koiralanamu@gmail.com \\ ORCID ID: https://orcid.org/0000-0003-3780-7820
}

\section{Citation}

Koirala N, Kafle SP. Attitude of Women and their Husbands Regarding Prenatal Invasive Testing Attending Genetic Clinic at A Tertiary Referral Center, India. BJHS 2020;5(3)13.1176-1180.

\section{ABSTRACT \\ Introduction}

Prenatal Invasive Tests (amniocentesis and chorionic villous sampling) are used during pregnancy for detection of genetic anomalies. Due to the fear of fetal loss or various other reasons, the couples who seek to avail these tests are usually in dilemma though the chances of fetal loss following the invasive tests are very minimal.

\section{Objectives}

To assess the attitude of high-risk pregnant women and their husbands regarding the prenatal invasive tests who are referred to the genetic clinic of a tertiary referral center in India.

\section{Methodology}

A descriptive, cross sectional study was undertaken in 60 pregnant women who came to genetic clinic at a tertiary referral center in India for counseling on the prenatal invasive testing. Convenience sampling technique was used. Data was collected using a self-developed, validated semi structured questionnaire. There were total 14 items in the questionnaire where the response "Yes" was given score 3, "Uncertain/did not think about it" was given score 2 and "No" was given score 1. Maximum score was 42 and minimum was 14 . The subjects were contacted by the principal investigator after the counseling for test was done by the trained counselor. The questionnaire was also administered separately to 49 accompanying husbands to assess their attitude regarding the tests. Mean, percentage, standard deviation, range and Pearson's correlation were calculated. SPSS 16.0 version was used for data analysis.

\section{Results}

Almost half of the women reported that they had adequate information regarding the test following counselling. Both the women and their husbands had unfavorable attitude towards the tests i.e. $21.98 \pm 5.44$ and $22.27 \pm 5.11$ respectively despite adequate information following counselling. The main reasons for declining the tests were fear of identification of birth defects, fear of termination of pregnancy and influence by other family members other than their husbands. There was a significant positive correlation between the attitude of women and their husbands towards declining the prenatal invasive tests $(r=0.973)$ at $p<0.05$.

\section{Conclusion}

The pregnant women as well as their husbands had unfavorable attitudes towards prenatal invasive tests despite adequate information following counselling suggesting congruency indecision making regarding the invasive tests.

\section{KEY WORDS}

amniocentesis, chorionic villi sampling, prenatal diagnosis 


\section{INTRODUCTION}

Pregnancy is a joyous moment for the women but a baby with genetic anomalies like Down's syndrome is likely to cause undue stress on personal, family life, relationships as well as parents' work. ${ }^{1}$ Due to a large population and high birth rate as well as consanguineous marriage favored in many communities, the prevalence of genetic disorders in India is very high. An estimated 21,400 babies with Down syndrome, 9,000 with $\beta$ - thalassaemia and 5,200 with sickle cell disease are born each year in India. Therefore, screening for chromosomal disorders is necessary to detect genetic abnormalities. The commonly used biochemical markers which can be carried out at 11-14 weeks of gestation are inhibin A, serum Alpha-Feto Protein (AFP), free Beta Human Gonadotropin(ß-hCG), total hCG, Pregnancy-Associated Plasma Protein A (PAPP-A), unconjugated estradiol (uE3). Other less common markers are Placental Growth Factor (PIGF), Placental Growth Hormone (PGH), Invasive Trophoblast Antigen (ITA), Growth Hormone Binding Protein (GHBP) and Placental Protein 13 (PP13). Ultrasonography, and other invasive as well as non-invasive prenatal diagnostic tests on the basis of presence of cell-free fetal DNA in maternal plasma are also used for screening. Screening should be carried out during pre-pregnancy stage itself. ${ }^{4}$ Commonly used invasive diagnostic tests during pregnancy for detection of Down's syndrome are amniocentesis or Chorionic Villous Sampling (CVS), with or without prior screening. These tests are nowadays referred as reference tests. These tests possess risk for miscarriage at around $0.35 \%$ to $1 \%$. The prenatal invasive tests which have been adopted in second trimester have been abundantly used since the 1980s. The results of first and second trimester screening programs have also increased the dilemmaforopting the tests in detecting chromosomal anomalies. ${ }^{7}$

A recent study done in France in 2018-19 showed that around $21 \%$ women expressed favorable attitude toward invasive testing with complete karyo typing. ${ }^{8}$ Similarly, in Romania it was found that $78.9 \%$ participants had a positive attitude for screening, $88 \%$ had insufficient knowledge and $68.3 \%$ made a value-consistent decision for the uptake of prenatal screening. ${ }^{9}$ A study conducted among twenty-three Asian women in the United States about their attitudes towards prenatal genetic testing showed the emergence of four themes: diverse expectations from genetic counselors, weighing of risks and benefits with regards to genetic testing decisions, having mixed views on termination for fatal and non- fatal genetic conditions. ${ }^{10}$ Another finding from Netherlands concluded that almost all women (99\%) in the high-risk group and $89 \%$ of women in the low-risk group were informed about invasive prenatal diagnostic procedures. ${ }^{11}$

In the last two decades, several studies have been conducted in India in different aspects of prenatal invasive testing such as the profile of women/couples who seek those tests and for gender identification. ${ }^{12}$ However, studies addressing the attitude of women having the fetal genetic risk factors and their husbands towards the testing is very scarce in developing countries.

The present study aimed to explore attitudes of pregnant women and their husbands who were about to make their decision regarding the prenatal invasive testing.

\section{METHODOLOGY}

A descriptive, cross sectional study was undertaken on 60 women with their accompanying husbands who came to genetic clinic, Department of Pediatrics at All India Institute of Medical Sciences (AIIMS), New Delhi for counseling regarding the prenatal invasive testing. The All India Institutes of Medical Sciences (AIIMS) are a group of autonomous government medical colleges of higher education among which AIIMS, New Delhi is a tertiary referral center located at New Delhi, northern part of India, which is also the capital of the country. Sample size was calculated using formula $\mathrm{N}=\mathrm{Z}^{\wedge} 2^{*} \mathrm{P}^{*} \mathrm{Q} / \mathrm{E}^{\wedge} 2$, where $\mathrm{N}=$ sample size, $\mathrm{Z}=\mathrm{Z}$ value i.e.1.96 for $95 \%$ confidence level, $P=$ percentage picking a choice, expressed as decimal which is 3.9 (there was 3.9\% of uptake of prenatal testing in the study) i.e. $0.039,{ }^{13} \mathrm{Q}=1-\mathrm{P}$, i.e. 0.961 , $\mathrm{E}=$ Margin of error which is 0.05 . We had planned to include same number of husbands, i.e. 60 women and 60 husbands but only 49 husbands accompanied the pregnant women during the counselling. Rest of the women came with other family members. The duration of this study was 6 months (March 2012 - September 2012). Sample included all pregnant women who were referred to genetic clinics at AlIMS, New Delhi for prenatal diagnostic testing (gestational age ranging from 15 weeks to 23 weeks) and who were willing to participate in the study. Convenience sampling was adopted for the study. We enrolled 10 subjects each month including minimum of 2 subjects in each week. Semi-structured questionnaire was separately administered to both women as well as their husbands which was a 3-point Likert scale and the choices were categorized into "Yes", "No", "Uncertain/ did not think about it". During the process of data collection, any doubts or queries arising from both respondents as well as principal investigator was made clear at the site. There were total 14 items in the questionnaire where the response "Yes" was given score 3, "Uncertain/did not think about it" was given score 2 and "No" was given score 1. Maximum score was 42 and minimum was 14 . The Higher scores depicted favorable attitude (of women and their husbands towards tests). The scores ranging from 14-28 was defined as unfavorable attitude and from 29-42 as highly favorable attitude towards the prenatal invasive tests. Validity was maintained by consulting with the experts. It was pretested among $10 \%$ of sample size, i.e. 6 pregnant women and 6 husbands. The pretested samples were excluded from the main study. Tool was constructed in English translated in Hindi and was again back translated in English. Ethical clearance for the study was obtained from Institute Ethics Committee/Ethics Sub-Committee, AIIMS, New Delhi, India. Information sheet was developed and given to the study participants. Informed consent was taken from all the 
subjects. Confidentiality of the subjects was maintained. Inclusion criteria for sample selection were: pregnant women who had fetal genetic risk factors and were referred to genetic clinics at AIIMS, New Delhi for prenatal diagnostic testing who could communicate in Hindi or English. For data analysis, descriptive statistical methods included mean, standard deviation, frequency, range and percentage. Inferential statistical methods included Pearson's correlation test. The level of significance was $p<0.05$. Data was entered in Microsoft EXCEL and analyzed using SPSS 16.0 version.

\section{RESULTS}

Nearly half the women (46.7\%) were in the age groups $21-$ 30 years followed by $31-40$ years age group (43.3\%). Majority of the women were from the urban residence (85\%) and Hindu by religion (75\%). All the women were literate and more than $30 \%$ of them had higher secondary level of education. Fifteen percent of the women had consanguineous marriage. Table no. 1 shows the socio demographic profile of the women attending genetic clinic.

\begin{tabular}{lll}
\multicolumn{2}{l}{$\begin{array}{l}\text { Table 1: Socio demographic characteristics of the women } \\
n=60\end{array}$} & \\
Variable & Category & Frequency (\%) \\
Age & $<20$ years & $2(3.3 \%)$ \\
& $21-30$ years & $28(46.7 \%)$ \\
& $31-40$ years & $26(43.3 \%)$ \\
& $>40$ years & $4(6.7 \%)$ \\
Residence & Rural & $9(15 \%)$ \\
Religion & Urban & $51(85 \%)$ \\
& Hindu & $45(75 \%)$ \\
& Muslim & $6(10 \%)$ \\
Education (women) & Christian & $6(10 \%)$ \\
& Sikh/others & $3(5 \%)$ \\
& Primary & $4(6.7 \%)$ \\
& Secondary & $12(20.0 \%)$ \\
Higher Secondary & $20(33.3 \%)$ \\
Type of marriage & Graduate & $14(23.3 \%)$ \\
& Postgraduate and above & $10(16.7 \%)$ \\
Type of family & Consanguineous & $9(15 \%)$ \\
& Non consanguineous & $51(85 \%)$ \\
& Joint & $40(66.7 \%)$ \\
& Nuclear & $20(33.3 \%)$ \\
& &
\end{tabular}

The obstetric characteristics of the women are depicted in the Table no. 2. The two most common reasons for referral were advanced maternal age i.e. above 35 years (38.3\%) followed by abnormal USG (30\%). More than two-thirds of the respondents (66\%) were pregnant for the second time. Majority (80\%) had no still birth in the past and $16.67 \%$ had 1 still birth previously. Interestingly 33.3\% of them reported that the pregnancy wasn't planned. Around $16.67 \%$ of the women stated that there was the history of genetic anomaly in the previous child.

\begin{tabular}{|c|c|c|}
\hline Variable & Category & uency (\%) \\
\hline Reasons for referral & $\begin{array}{l}\text { Advanced maternal age } \\
\text { Abnormal USG } \\
\text { Abnormal biochemical } \\
\text { marker } \\
\text { Multiple termination of } \\
\text { pregnancies } \\
\text { Previous affected child }\end{array}$ & $\begin{array}{l}23(38.3 \%) \\
18(30.0 \%) \\
10(16.7 \%) \\
\\
2(3.3 \%) \\
7(11.7 \%)\end{array}$ \\
\hline Total no of pregnancies & $\begin{array}{l}1 \\
2 \\
\geq 3\end{array}$ & $\begin{array}{l}12(20 \%) \\
40(66.7 \%) \\
8(13.3 \%)\end{array}$ \\
\hline Prior still birth(s) & $\begin{array}{l}0 \\
1 \\
\geq 2\end{array}$ & $\begin{array}{l}48(80 \%) \\
10(16.67 \%) \\
2(3.33 \%)\end{array}$ \\
\hline Prior miscarriage(s) & $\begin{array}{l}0 \\
1 \\
\geq 2\end{array}$ & $\begin{array}{l}53(88.3 \%) \\
4(6.7 \%) \\
3(5 \%)\end{array}$ \\
\hline $\begin{array}{l}\text { Prior induced termination } \\
\text { of pregnancy(s) }\end{array}$ & $\begin{array}{l}0 \\
\geq 1\end{array}$ & $\begin{array}{l}56(93.3 \%) \\
4(6.7 \%)\end{array}$ \\
\hline Pregnancy planned & $\begin{array}{l}\text { Yes } \\
\text { No }\end{array}$ & $\begin{array}{l}40(66.7 \%) \\
20(33.3 \%)\end{array}$ \\
\hline $\begin{array}{l}\text { Previously affected child } \\
\text { with genetic anomaly }\end{array}$ & $\begin{array}{l}\text { Yes } \\
\text { No }\end{array}$ & $\begin{array}{l}10(16.67 \%) \\
50(83.33 \%)\end{array}$ \\
\hline
\end{tabular}

Table no. 3 shows the attitude of women towards the PIT. Nearly two-thirds of the women (63.27\%) said that they had enough support from other family members to make a choice. Likewise, $89.8 \%$ of the respondents said that they were choosing without pressure from others. Majority of the respondents (85.71\%) believed that their decision was not influenced by religion or culture and $81.63 \%$ of the women reported that they will opt testing in future pregnancies also. But, majority of the respondents $(89.80 \%)$ were worried as they were offered the test.

\section{Table 3: Attitude of women towards prenatal invasive tests $n=60$}

\footnotetext{
Components of attitude

Components of attitude
Know which options are available
Know the risks and side effects of each option
Clear about the best choice
Aware of benefits of test
Clear about which benefits matter most
Feel sure about what to choose
Have enough support from others to make a choice
Choosing without pressure from others
Think decision(s) is/are not influenced by religion or culture
Want to take test in future pregnancies
Not worried as offered screening test
Consider termination of pregnancy if fetus has any defect
Think that prenatal invasive testing is useful
}

\section{Responses (Frequency \%)}

Yes No

Uncertain/didn't think about

$\begin{array}{lll}23(46.94 \%) & 7(14.29 \%) & 19(38.77 \%) \\ 34(69.39 \%) & 9(18.37 \%) & 6(12.24 \%) \\ 38(77.55 \%) & 4(8.16 \%) & 7(14.29 \%) \\ 36(73.47 \%) & 3(6.12 \%) & 10(20.41 \%) \\ 39(79.59 \%) & 3(6.12 \%) & 7(14.29 \%) \\ 37(75.51 \%) & 6(12.24 \%) & 6(12.24 \%) \\ 37(75.51 \%) & 5(10.20 \%) & 7(14.29 \%) \\ 31(63.27 \%) & 3(6.12 \%) & 15(30.61 \%) \\ 44(89.80 \%) & 0 & 5(10.20 \%) \\ 42(85.71 \%) & 2(4.08 \%) & 5(10.20 \%) \\ 28(57.14 \%) & 3(6.12 \%) & 18(36.73 \%) \\ 3(6.12 \%) & 44(89.80 \%) & 2(4.08 \%) \\ 40(81.63 \%) & 1(2.04 \%) & 8(16.33 \%) \\ 42(85.71 \%) & 1(2.05 \%) & 6(12.24 \%)\end{array}$


Table no. 4 depicts the attitude of husbands towards the test. Majority of the husbands (76.7\%) responded that they knew the risks and side effects of each option. Most of the husbands (75\%) said that they were clear about the best option for PIT.

$\begin{array}{llll}\text { Table 4: Attitude of the husbands regarding the prenatal invasive testing } n=49 & & \text { No } & \begin{array}{l}\text { Uncertain/didn't } \\ \text { think about it }\end{array} \\ & & \text { Yes } & 23(38.3 \%) \\ \text { Have enough information to make decision } & 30(50 \%) & 7(11.7 \%) & 7(11.7 \%) \\ \text { Know which options are available } & 43(71.7 \%) & 10(16.7 \%) & 9(15.0 \%) \\ \text { Know the risks and side effects of each option } & 46(76.7 \%) & 5(8.3 \%) & 11(18.3 \%) \\ \text { Clear about the best choice } & 45(75.0 \%) & 4(6.7 \%) & 8(13.3 \%) \\ \text { Aware of benefits of test } & 47(78.3 \%) & 5(8.3 \%) & 10(16.7 \%) \\ \text { Clear about which benefits matter most } & 44(73.3 \%) & 6(10.0 \%) & 10(16.6 \%) \\ \text { Feel sure about what to choose } & 46(76.7 \%) & 4(6.7 \%) & 20(33.4 \%) \\ \text { Have enough support from others to make a choice } & 38(63.3 \%) & 2(3.3 \%) & 7(11.7 \%) \\ \text { Choosing without pressure from others } & 53(88.3 \%) & 0 & 5(8.4 \%) \\ \text { Think decision(s) is/are not influenced by religion or culture } & 53(88.3 \%) & 2(3.3 \%) & 19(31.6 \%) \\ \text { Want to take test in future pregnancies } & 37(61.7 \%) & 4(6.7 \%) & 2(3.3 \%) \\ \text { Not worried as offered screening test } & 4(6.7 \%) & 54(90.0 \%) & 6(10.0 \%) \\ \text { Consider termination of pregnancy if fetus has any defect } & 53(88.3 \%) & 1(1.7 \%) & 8(13.3 \%)\end{array}$

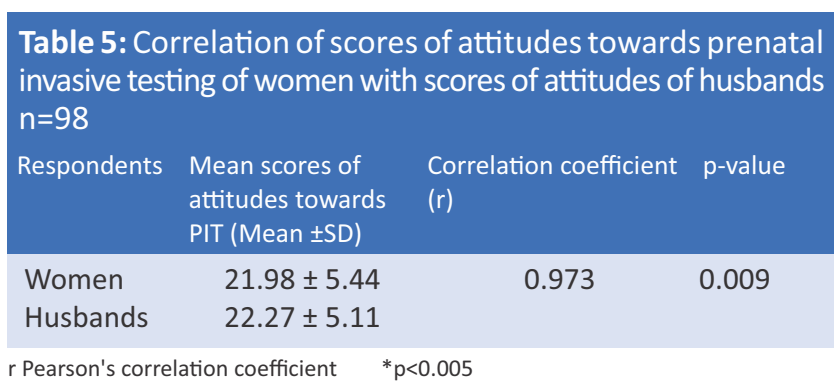

The reasons for not undergoing the testing as reported by the women were fear of identification of birth defects (50\%), followed by fear of termination of pregnancy (30\%) and influence of family members (20\%).

\section{DISCUSSION}

In this study, the attitude of the high-risk pregnant women following counselling was unfavorable towards the prenatal invasive tests despite the fact that majority of the pregnant women were from urban area with higher education and in the age group of 21-30 years. Similar demographic profiles were observed in the studies done by Tsai GJ, et $\mathrm{al}^{10}$ where $48 \%$ of women were below the age of 30 years and by Graaf IM De et al where around $80 \%$ of the women were from the urban residence. ${ }^{11,14,5}$ It is also important to note that post counselling; both women and husbands had unfavorable attitude towards the prenatal invasive tests in spite of the reporting that their knowledge and understanding was adequate and both of them were mature enough to make the decisions on their own.

The questionnaire was also administered separately to their accompanying husbands which also revealed the unfavorable attitude toward the PITs; which is statistically significantly correlated and is congruent to the attitude of their wives. This is against the general belief of Asian model of paternalistic dominance in health care and decisionmaking process. ${ }^{16}$
In our study, consanguineous marriages in high risk pregnant women were relatively more common accounting $15 \%$ whereas it was very low in the study by Tsai GJ, et al ${ }^{10}$ where only $1 \%$ of them had consanguineous marriage. This may be due to consanguineous marriage being common in Muslims which were second to Hindu in our study by religion.

The major reasons for referral were advanced maternal age (38.3\%) followed by abnormal USG (30.0\%), abnormal biochemical marker, multiple spontaneous termination of pregnancies and previously affected child. Though Majority (66\%) were pregnant for the second time and $80 \%$ had no still birth in the past. Only, $16.67 \%$ respondents reported that they had one still birth which is lesser than that of the study done by Mikamo S. ${ }^{16}$ The lesser figures of still births and miscarriages in the present study might be due the fact that advanced maternal age followed by abnormal USG were the major reasons for referral unlike the other studies ${ }^{14,17}$ where previous history of affected child and previous miscarriage(s)/still births accounted major reasons for referral.

Nearly half of the women reported that they had enough information to make decision which is lesser than the study done in Netherlands. ${ }^{12}$ This might be because of the social and cultural influence while making decision and seeking the opinion from other family members and close relatives in the present study. Fifty seven percent of the women opted for testing in future pregnancies if required which is congruent to study done by Bryant L. ${ }^{17}$ Eighty five percent of the women reported that the religion has no influence on their decision regarding the test and this finding is contrary to the study done in France. ${ }^{8}$ This might be because of the fact that the Catholics have very strong religious beliefs and their religion guides most of the decisions in life.

In this study, $81 \%$ of the women reported that they would consider termination of pregnancy if the fetus had any defect which is similar to the finding of another study. ${ }^{18}$ The 
major reasons for not undergoing the testing as reported by the women were fear of identification of birth defects (50\%), followed by fear of termination of pregnancy $(30 \%)$ and influence of family members (20\%).

\section{CONCLUSION}

The women as well as their husbands had unfavorable attitude towards the PIT. So, better knowledge regarding the procedure and associated risk of complications of the prenatal invasive test improves the decision making of women for opting the prenatal invasive testing.

Hence, similar studies can be done in other similar low- and middle-income countries having similar religion, ethnicity as well as educational background with larger sample size for generalizing the outcomes of the study. The health personnel (doctors and nurses) should take into account these facts that proper counseling has to be done as soon as the women are referred for the invasive tests and this will facilitate the women in better decision making.

\section{LIMITATIONS OF STUDY}

Sample size is small. Findings of the study may not be generalized to other settings as it was done at a single site in India.

Implications of the study are that the health personnel (doctors and nurses) should be sensitized for the need for genetic counseling so that they can: a) Generate more dedicated counsellors mainly through Continuing Medical/ Nursing Education and in-service programs, b) Assign adequate personnel to these areas (e.g. genetic OPD) in order to function effectively.

\section{ACKNOWLEDGEMENT}

We would like to acknowledge Dr. Manju Vatsa, Principal, College of Nursing AIIMS, New Delhi, Dr. Madhulika Kabra, Professor and Officer-In charge, Genetic Unit, department of Pediatrics, AlIMS, New Delhi and Ms. Kamlesh K. Sharma, Lecturer, College of Nursing AlIMS, New Delhi for their invaluable support in carrying out this study. This study wouldn't have been possible without the time and participation of the women and their husbands who provided their invaluable information for the study.

\section{CONFLICT OF INTEREST}

There is no any conflict of interest during the study.

\section{FINANCIAL DISCLOSURE}

We didn't receive any financial support for the conduction of this research as well as to prepare this article.

\section{REFERENCES}

1. Al-Yagon M, Margalit M. Children with Down Syndrome: Parents' Perspectives. Oxford Handb Intellect Disabil Dev. 2012;(August 2014).

2. Verma IC, Bijarnia S. The Burden of Genetic Disorders in India and a Framework for Community Control. Community Genet [Internet]. 2002 [cited 2020 Jan 28];5(3):192-6. Available from: https://www. karger. com/Article/FullText/66335

3. Alldred SK, Takwoingi Y, Guo B, Pennant M, Deeks JJ, Neilson JP, et al. First trimester ultrasound tests alone or in combination with first trimester serum tests for Down's syndrome screening. Vol. 2017, Cochrane Database of Systematic Reviews. John Wiley and Sons Ltd; 2017.

4. Verma IC, Puri RD. Global burden of genetic disease and the role of genetic screening. Vol. 20, Seminars in Fetal and Neonatal Medicine. W.B. Saunders Ltd; 2015. p. 354-63.

5. Tara $F$, Lotfalizadeh $M$, Moeindarbari $S$. The effect of diagnostic amniocentesis and its complications on early spontaneous abortion. Electron physician. 2016 Aug 25;8(8):2787-92.

6. Beta J, Lesmes-HereDia C, Bedetti C, Akolekar R. Risk of miscarriage following amniocentesis and chorionic villus sampling: A systematic review of the literature. Vol. 70, Minerva Ginecologica. Edizioni Minerva Medica; 2018. p. 215-9.

7. Kuppermann M, Learman LA, Gates E, Gregorich SE, Nease RF, Lewis J, et al. Beyond Race or Ethnicity and Socioeconomic Status. Obstet Gynecol. 2006;107(5):1087-97.

8. Seror V, L'Haridon O, Bussières L, Malan V, Fries N, Vekemans M, et al. Women's Attitudes Toward Invasive and Noninvasive Testing When Facing a High Risk of Fetal Down Syndrome. JAMA Netw open. 2019;2(3):e191062.

9. Pop-Tudose ME, Popescu-Spineni D, Armean P, Pop IV. Attitude, knowledge and informed choice towards prenatal screening for Down Syndrome: a cross-sectional study. [cited 2020 Jan 28]; Available from: https://doi.org/10.1186/s12884-018-2077-6
10. Tsai GJ, Cameron CA, Czerwinski JL, Mendez-Figueroa H, Peterson SK, Noblin SJ. Attitudes Towards Prenatal Genetic Counseling, Prenatal Genetic Testing, and Termination of Pregnancy among Southeast and East Asian Women in the United States. J Genet Couns [Internet]. 2017 Oct 2 [cited 2020 Jan 28];26(5):1041-58. Available from: http://doi.wiley.com/10.1007/s10897-017-0084-9

11. Graaf IM De, Tijmstra T, Bleker OP, Lith JMM Van. Womens preference in Down syndrome screening. 2002;(July 2001):624-9.

12. Gupta JA. Exploring Indian women's reproductive decision-making regarding prenatal testing. Cult Heal Sex. 2010 Feb;12(2):191-204.

13. Kleijer WJ, van der Sterre MLT, Garritsen VH, Raams A, Jaspers NGJ. Evolution of prenatal detection of neural tube defects in the pregnant population of the city of Barcelona from 1992 to 2006. Prenat Diagn. 2011;31(10):1184-8.

14. Wal JTG Van Der, Verhoeven PS, Manniën J, Martin L, Reinders HS, Spelten $E$, et al. Factors affecting the uptake of prenatal screening tests for congenital anomalies; a multicentre prospective cohort study. 2014;

15. Abdo N, Ibraheem N, Obeidat N, Graboski-Bauer A, Batieha A, Altamimi $\mathrm{N}$, et al. Knowledge, Attitudes, and Practices of Women Toward Prenatal Genetic Testing. Epigenetics Insights. 2018 Dec 1;11.

16. Mikamo S, Nakatsuka M. Knowledge and attitudes toward noninvasive prenatal testing among pregnant Japanese women. Acta Med Okayama. 2015;69(3):155-63.

17. Bryant L, Hewison JD, Green JM. Attitudes towards prenatal diagnosis and termination in women who have a sibling with Down's syndrome. J Reprod Infant Psychol. 2005 May;23(2):181-98.

18. Tischler R, Hudgins L, Blumenfeld YJ, Greely HT, Ormond KE. Noninvasive Prenatal Diagnosis: Pregnant Women's Interest and Expected Uptake NIH Public Access. Prenat Diagn. 2011;31(13):1292-9. 